\title{
Parietal Lobe Abscess Resulting from Penicillium Marneffei Infection in an Immunocompetent Nigerian: Case Report and Review of Literature
}

\author{
Usiholo E A, Osabuohien K O, Badejo O A, Odebode T O* \\ Neurosurgical Unit, Department of Surgery, University of Ilorin Teaching Hospital, Ilorin. Nigeria \\ *Corresponding Author: T.O. Odebode, Division of Neurosurgery, Department of Surgery, University of \\ Ilorin Teaching Hospital, Kwara state, Nigeria, Email: odebodetodr@yahoo.com
}

\begin{abstract}
Penicillium marneffei is an emerging and uncommon medically important fungal pathogen but the third most common cause of opportunistic infection in HIV-infected immune compromised patients in parts of South East Asia where Penicilliosis is endemic. Infected patients commonly present with fever, weight loss, skin lesions and respiratory features but central nervous system involvement is very rare. We report an immune competent Nigerian adult who presented with non-specific symptoms of headache and seizure and non-specific cranial CT findings. but histopathological verification of the pus drained by bore holecraniostomy from a left parietal lobe abscess revealed Penicillium marneffei infection. She was successfully treated postoperatively with sensitive antifungal fluconazole and she has remained clinically stable till date. This is the first of its kind in this center which serves about six constituent states of Nigeria over 17 years of inception of Neurosurgical service. The report illustrates the rarity of Penicillium marneffei infection in immune competent individuals (outside the shores of South East Asia). It also highlights its uncommon predilection for the central nervous system; especially in patients presenting with non-specific clinical and neuro-radiologic features; a situation which calls for a high index of suspicion for its diagnosis. We report the first case of an immunocompetent Nigerian diagnosed with parietal lobe abscess resulting from Penicillium marneffei infection.
\end{abstract}

Keywords: Penicillium marneffei, Penicilliosis, CNS fungal infection, brain abscess

\section{INTRODUCTION}

Although intracranial abscesses are relatively common in developing countries of the world including Nigeria, majority of reported cases were due to bacterial organisms; with only a few resulting from fungal organisms ${ }^{1}$ usually in immunocompromised patients ${ }^{2}$. Penicillium marneffei infection or Penicilliosis is one of the recently emerging systemic fungal infections, in individuals infected with human immuno deficiency virus (HIV). It is an endemic dimorphic fungus in tropical Asia, especially Thailand, northeastern India, China, Hong Kong, Vietnam, and Taiwan ${ }^{3-7}$. While a single case of the disease has also been observed in an African from Ghana who had no history of travel to southeast $\mathrm{Asia}^{8}$, no further cases have been reported, suggesting that $P$. marneffei is in fact endemic to southeast Asia. The organism is a relatively a recent addition to known southeast Asian mycoses, being discovered in 1956 as an infection of bamboo rats 9 . However, the importance of $P$. marneffe $i$ as a human disease was recognized only when the HIV pandemic arrived in Asia and the prevalence of infection increased in local populations as well as in visitors from areas where the infection is not endemic $^{10-12}$. The disease is, after tuberculosis and cryptococcosis, the third most common opportunistic infection in patients with AIDS in northern Thailand ${ }^{7}$. Penicillium marneffei is the only known Penicillium species that exhibits temperature-dependent dimorphic growth. At temperatures below $37^{\circ} \mathrm{C}$, the fungus grows as mycelia with the formation of septate hyphae, bearing conidiophores and conidia typical of the genus Penicillium. At $37^{\circ} \mathrm{C}$ on artificial medium or in human tissue, the fungus grows in a yeastlike form with the formation of fission arthroconidium cells. The fission yeast cells represent the parasitic form of $P$. marneffei. Its enigmatic natural history needs to be further characterized. The fourth case of Peniciliumspp CNS infection HIV-negative individuals was reported in 2005 in a 41-year-old Brazilian patient with multiple brain abscesses caused by 
a member of the Penicillium genera. ${ }^{13}$. It is rare in HIV-negative individuals, the central nervous system and in tropical Africa. To the best of our knowledge this report constitutes the first of a fungal CNS infection by Penicillium marneffei in an immunocompetent patient from Nigeria and West Africa at large.

\section{CASE REPORT}

We present a case of central nervous system (CNS) infection by. Penicillium marneffei in a HIV-negative immunocompetent 60-year-old woman from Ilorin, in Nigeria. The patient was admitted into the emergency service of the hospital complaining of headache and right sided tonic-clonic seizures of 3 months and 3 weeks respectively. She had a background history of hypertension but denied history of fever, weight loss, chronic cough, chest pain, dyspnea, bone ache, ear or nasal discharge or skin lesions. An initial clinical assessment revealed a conscious woman (Glasgow coma scale score $=15$ ) with a right sided supra-nuclear facial nerve palsy and subtle right hemiparesis. She lacked any of the dermatological, respiratory, cardiovascular, or gastrointestinal features commonly associated with systemic Penicilliosis. The hematological and biochemical profiles were essentially normal with a fasting blood sugar of $98 \mathrm{mg} \%$. No radiographic abnormalities in the chest. Third generation antibody (ELISA antibody) and fourth generation antibody/ p24 antigen [ELISA combined antigen/antibody] tests were negative for HIV-1 and HIV-II antibodies. Cranial CT scan revealed a left sided mixed density parietal intracranial mass lesion with central hypo density, ring enhancement, effaced left lateral ventricle and right anterior horn, plus perilesional edema extending into the ipsilateral frontal lobe and producing a midline shift (Fig 1). The seizures were controlled with phenytoin sodium; 300mg 8 hourly for the first 24 hours; and thereafter $300 \mathrm{mg}$ nocte. The patient subsequently underwent a left parietal craniotomy and gross total excision of a well encapsulated and circumscribed parietal lobe abscess. The overlying dura was thickened and there was marked cerebral edema. Histopathology of the excised mass lesion revealed a well-organized pyogenic abscess; while culture yielded a growth of Penicillium marneffei; sensitive to fluconazole. The patient was commenced post-operatively on slow intravenous infusion of fluconazole injection $300 \mathrm{mg}$ stat; which was administered slowly over 1-2 hours and thereafter at $150 \mathrm{mg}$ daily for 14 days. She improved remarkably clinically and was discharged with satisfactory surgical outcome after four weeks of hospitalization. She has remained clinically stable enjoying normal quality of life and without any neurological deterioration till date.

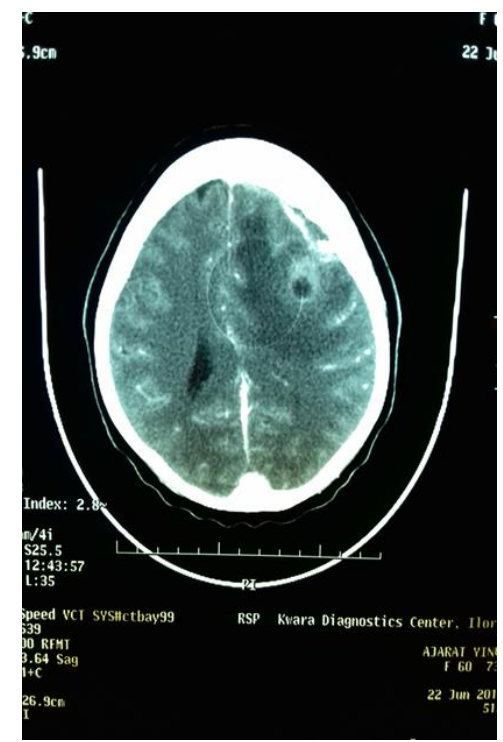

Fig1. Cranial CT of the 60-year-old woman showing a left sided mixed density parietal intracranial mass lesion with central hypo density, ring enhancement, effaced left lateral ventricle and right anterior horn, significant perilesional edema with frontal extension and a midline shift

\section{DISCUSSION}

Penicilliosis marneffei is a disseminated and progressive infection caused by Penicillium marneffei, a facultative intracellular pathogen and the only thermally dimorphic fungus of the genus Penicillium ${ }^{3,14,15}$. It is the third most common opportunistic infection in HIV-infected patients in certain parts of Southeast Asia ${ }^{15}$. Areas in which the organism is highly endemic include Southeast Asia ${ }^{16,17,18}$ and the southern part of China, ${ }^{3,}$. Cases from outside the region of endemicity were observed in HIV-infected patients from Australia, Belgium, France, Germany, Japan, Sweden, Switzerland, The Netherlands, the United Kingdom, and the United States ${ }^{20}$.

The organism was first isolated in 1956 from the liver of a bamboo rat (Rhizomyssinensis) in Vietnam $^{16}$ and was named after Dr. Hubert Marneffe, director of the Institut Pasteur in Indochina and Paris ${ }^{21}$. The first human infection was reported in $1959^{18}$ after a researcher accidentally inoculated himself and cultured the fungi from a subsequent lymph node 
enlargement nine days later. Deng and colleagues $^{3}$ identified the first patient with naturally occurring penicilliosis marneffei in Guangxi, China, in 1964. Five cases were reported in Bangkok, Thailand by Jayanetra et $\mathrm{al}^{17}$. Two of these patients were immune competent and were successfully treated with amphotericin B.

Penicillium marneffei is the only known Penicillium species that exhibits temperaturedependent dimorphic growth. At temperatures below $37^{\circ} \mathrm{C}$, the fungus grows as mycelia with the formation of septate hyphae, bearing conidiophores and conidia typical of the genus Penicillium. At $37^{\circ} \mathrm{C}$ on artificial medium or in human tissue, the fungus grows in a yeast-like form with the formation of fission arthro conidium cells. The fission yeast cells represent the parasitic form of $P$. marneffei. This form is seen in the intracellular infection of the macrophages. The mold-to-yeast conversion or phase transition, which is thermally regulated, is a diagnostic characteristic of P.marneffei. In contrast to P. marneffei, the other Penicillium species are not dimorphic and are more like Aspergillus, with hyphae in tissue ${ }^{20,22}$. Between June 1990 and June 2004, 1,843 cases of disseminated $P$. marneffei infection were seen in HIV-infected patients at Chiang Mai University Hospital. Approximately 6,709 cases of $P$. marneffei infection were diagnosed in Thailand between September 1984 and October 2004 ${ }^{23}$.

Our patient presented with non-specific symptoms of headache and seizures but most documented cases presented with fever, weight loss, skin lesions, generalized lymphadenopathy, respiratory signs and hepatomegaly ${ }^{24}$ which were completely absent in this case. It is possible that CNS involvement may not manifest clinically like other systemic involvements.

In the absence of skin lesions, it was difficult to unequivocally attribute her clinical findings to $P$. marneffei infection alone. Mucocutaneous, oral, and facial manifestations that have been reported in patients with $P$. marneffei infection ${ }^{25}$ were absent in this patient. Most such lesions are molluscum contagiosum-like umbilicated papules mainly distributed over the face and upper trunk ${ }^{26}$.

Penicillium marneffei can be isolated from various clinical specimens by direct mycological examination or cultures as it was done in this patient. Specimens stained with Wright, Giemsa or Periodic Acid Schiff's demonstrate intracellular and extracellular basophilic, spherical, oval to elliptical, yeast-like organisms ( $3 \pm 8 \mathrm{~mm}$ in diameter), with clear transverse section characteristic of P.marneffei yeast phase. Culture specimens from bone marrow aspiration and lymph node biopsy are the most sensitive $(100 \%)$, followed by skin tissue $(90 \%)$ and blood (76\%), respectively ${ }^{24}$. The latter investigations could not have been carried out in this patient since her symptomatology was in no way specific for penicillosis. Even the cranial CT scan features were non-specific for penicillosis; pointing more to a diagnosis of a non-specific intracranial abscess of an uncertain etiology or a gliomatous tumor. The investigation was prompted by the presence of left sided seizure and hemiparesis.

Extensive review of the English literature revealed only four cases of reported intracranial infection with Penicillium marneffei, with two of them in non-immunocompromised patients ${ }^{26}$, $28,29,30$. The first case of intracranial infection resulted from a local spread from primary orbital-sinus infection causing a mycotic cerebral aneurysm and eosinophilic CSF pleocytosis. In the second case, intracranial Penicillium infection followed a primary lung involvement in a patient with acute leukemia. The third case (reported in India) was the first to result from hematogenous dissemination in a non-immunocompromised patient. The fourth case was a patient with chronic liver disease caused by long term HBV infection who presented in a hospital in Brazil. Our patient did not demonstrate any significant underlying disease and the chest X-ray did not reveal any occult chest lesion.

\section{CONClusion}

This report and review of literature illustrate the rarity of Penicillium marneffei infection in immunocompetent individuals outside the shores of South East Asia. It also highlights its uncommon predilection for the central nervous system; especially in patients presenting with non-specific clinical and neuro-radiologic features; a situation which calls for a high index of suspicion for its diagnosis. To the best of our knowledge, we present the fifth documented case worldwide of intracranial infection by Penicillium marneffei in an immune competent patient and the first from Nigeria and Africa at large. 


\section{REFERENCES}

[1] Muzumdar D, Jhawar S, Goel A. Brain abscess: an overview. Int. J Surg. 2011; 9:136-44.

[2] Scully EP, Baden LR, Katz JT. Fungal brain infections. Current Opinion in Neurology. 2008; 21:347-352.

[3] Chiang, C. T., H. S. Leu, T. L. Wu, and H. L. Chan. 1998. Penicillium marneffei fungemia in an AIDS patient: the first case report in Taiwan. Chan. Keng. I. Hsueh. 21:206-210

[4] Deng, Z. L., J. L. Ribas, D. W. Gibson, and D. H. Connor. 1988. Infections caused by Penicillium marneffei in China and Southeast Asia. Review of eighteen cases and report of four more Chinese cases.Rev. Infect. Dis. 10:640-652.

[5] Hien, T. V., P. P. Loc, N. T. T. Hoa, N. M. Duong, V. M. Quang, M. M. McNeil, N. T. Dung, and D. A. Ashford. 2001. First case of disseminated Penicilliosis marneffei infection among patients with acquired immunodeficiency syndrome in Vietnam. Clin. Infect. Dis. 32: e78-80.

[6] Ranjana, K. H., K. Priyokumar, T. J. Singh, Ch. C. Gupta, L. Sharmila, P. N. Singh, and A.

Chakrabarti. 2002.

Disseminated Penicillium marneffei infection among HIV-infected patients in Manipur state, India. J. Infect. 45:268-271.

[7] Supparatpinyo, K., C. Khamwan, V. Baosoung, K. E. Nelson, and T. Sirisanthana. 1994. Disseminated Penicillium marneffei infection in Southeast Asia. Lancet 344:110-113.

[8] Lo, Y., K. Tintelnot, U. Lippert, and T. Hoppe. 2000. Disseminated Penicillium marneffei infection in an African AIDS patient. Trans. R. Soc. Trop. Med. Hyg. 94: 187.

[9] Segretain, G. 1959. Description d'une nouvelle espèce de penicillium: Penicillium marneffei $\mathrm{n}$. sp. Bull. Soc. Mycol. Fr. 75:412-416.

[10] Hilmarsdottir, I., J. L. Meynard, O. Rogeaux, G. Guermonprez, A. Datry, C. Katlama, G. Bruecker, A. Coutellier, M. Danis, and M. Gentilini. 1993. Disseminated Penicillium marneffei infection associated with human immuno-deficiency virus: a report of two cases and a review of 35 published cases. J. Acquir. Immune Defic. Synd. 6: 466-471

[11] Peto, T. E. A., R. Bull, P. R. Millard, D. W. Mackenzie, C. K. Campbell, M. E. Haines, and R. G. Mitchell. . Systemic mycosis due to Penicillium marneffei in a patient with antibody to human immunodeficiency virus. J. Infect. 1988;16: 285-290.
[12] Viviani, M. A., A. M. Tortorano, G. Rizzardini, T. Quirino, L. Kaufman, A. A. Padhye, and L. Ajello. 1993. Treatment and serological studies of an Italian case of penicilliosis marneffei contracted in Thailand by a drug addict infected with the human immunodeficiency virus. Eur. J. Epidemiol. 9: 79-85.

[13] Danilo Teixeira Noritomi, Guilherme Linhares Bub, Idal Beer, Aloísio Souza Felipe da Silva, Roberto De Cleva \& Joaquim José GamaRodrigues. Case Report: Multiple brain abscesses due to Penicillium spp infection Rev. Inst. Med. trop. S. Paulo 47(3):167-170, MayJune, 2005

[14] Hilmarsdottir I, Meynard JL, Rogeaux 0, et al. Disseminated Penicillium marneffei infection associated with human immunodeficiency virus: a report of two cases and a review of 35 published cases. J Acquir Immune DeficSyndr. 1993; 6:466-71.

[15] Supparatpinyo K, Khamwan C, Baosoung V, Nelson KE, Sirisanthana T. Disseminated Penicillium marneffei infection in Southeast Asia. Lancet. 1994; 344:110-3.

[16] Capponi M, Sureau P, Segretain S. Penicilliose de Rhizomyssinensis. Bull SocPatholExot. 1956; 49:418 - 21.

[17] JayanetraP, Nityanant P, Ajello L. Penicillosis Marneffei in Thailand: report of five human cases. Am. J Trop Med Hyg. 1984; 33:63744.

[18] Segretain G.Penicillium marneffei n. sp., agent d'unemycoses dusysteme reticuloendothelial. MycopatholMycol Appl. 1959; 11:327-53.

[19] Deng Z, Yun M, Ajello L. Human Penicilliosis marneffei and its relation to the bamboo rat (Rhizomyspruinosus). J. Med Vet Mycol 1986; 24: 383-9.

[20] Tuan A. D. Infection Due to Penicillium marneffei, an Emerging Pathogen: Review of 155 Reported Cases. Clin Infect Dis. 1996: 23: 125-130.

[21] DiSalvo AF, Fickling AM, Ajello L. Infection caused by Penicillium marneffei: description of first natural infection in man. Am J ClinPathol 1973; 60:259-63?

[22] Vanittanakom N, Cooper C R, Fisher M C, Sirisanthana T. Penicillium marneffei Infection and Recent Advances in the Epidemiology and Molecular Biology Aspects. Clin. Microbiol. Rev. 2006; 19: 95-110.

[23] http://epid.moph.go.th

[24] Sirisanthana T, Supparatpinyo K. Epidemiology and management of penicilliosis in human immunodeficiency virus-infected patients. Int. J. infect. Dis. 1998; 3: 48-53. 
Parietal Lobe Abscess Resulting from Penicillium Marneffei Infection in an Immunocompetent Nigerian: Case Report and Review of Literature

[25] Wong SS, Wong KH, Hui WT. Differences in clinical and laboratory diagnostic characteristics of penicilliosis marneffei in human immunodeficiency virus(HIV)- and non-HIV-infected patients. J. Clin Microbiol. 2001; 39: 4535-4540.

[26] Noritomi DT, Bub GL, Beer I, da Silva AS, de Cleva R, Gama-Rodrigues JJ. Multiple brain abscesses due to Penicillium spp infection. Rev Inst Med Trop Sao Paulo. 2005; 47:167-70.

[27] Huang SN. Acute disseminated penicilliosis. Report of a case and review of the pertinent literature. Amer. J. Clin. Path. 1963; 39: 167174.
[28] Lyratzopolus G, Ellis S, Nerringer R, Denning DW. Invasive infection due to Penicillium species other than P. marneffei. J. Infection. 2002; 45: 184-207.

[29] Morris FH, Spock A, Durham N. Intracranial aneurysm secondary to mycotic orbital and sinus infections. Amer. J. Dis. Child. 1970; 119: 357-362.

[30] Ye F, Luo Q, Zhou Y, Xie J, Zeng Q, Chen G, $\mathrm{Su} \mathrm{D}$, Chen R. Disseminated penicilliosis marneffei in immune competent patients: a report of two cases. Indian J Med Microbiol. 2015; 33: 161-5.

Citation: Usiholo E A, Osabuohien K O, Badejo O A, Odebode T O. Parietal Lobe Abscess Resulting from Penicillium Marneffei Infection in an Immuno competent Nigerian: Case Report and Review of Literature. ARC Journal of Clinical Case Reports.2017; 3(3):15-19. doi:dx.doi.org/10.20431/2455-9806.0303004.

Copyright: (C) 2017 Authors. This is an open-access article distributed under the terms of the Creative Commons Attribution License, which permits unrestricted use, distribution, and reproduction in any medium, provided the original author and source are credited. 